International Journal of Current Advanced Research

ISSN: O: 2319-6475, ISSN: P: 2319 - 6505, Impact Factor: SJIF: 5.995

Available Online at www.journalijcar.org

Volume 6; Issue 5; May 2017; Page No. 3909-3912

DOI: http://dx.doi.org/10.24327/ijcar.2017.3912.0394

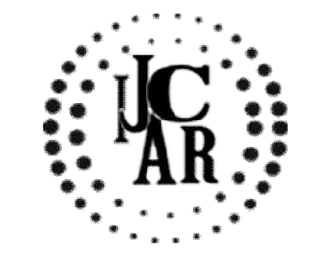

Research Article

\title{
CLIMATE CHANGE AND TERRITORY GOVERNANCE INSTRUMENTS
}

\author{
Brunella Brundu*
}

Department of Economics and Business (DiSEA) - University of Sassari, Italy

A R T I C L E I N F O

Article History:

Received $6^{\text {th }}$ February, 2017

Received in revised form $12^{\text {th }}$ March, 2017

Accepted $20^{\text {th }}$ April, 2017

Published online $28^{\text {th }}$ May, 2017

\section{Key words:}

Climate change, economic impacts, governance, GIS, Bayesian network

\begin{abstract}
A B S T R A C T
In the management of adaptation and mitigation processes for climate change, it is important to find appropriate governance tools. In this work we propose a GIS-based system, based on an intelligent probabilistic model. The model operates on climate, environmental and socio-economic data. The proposed system performs sophisticated analysis through spatial queries and provides useful answers to the territorial governance. It could be used to define territorial policies in order to mitigate or adapt the social and economic choices to the climate change.
\end{abstract}

Copyright $₫ 2017$ Brunella Brundu. This is an open access article distributed under the Creative Commons Attribution License, which permits unrestricted use, distribution, and reproduction in any medium, provided the original work is properly cited.

\section{INTRODUCTION}

\section{From environment to climate}

Environment and climate are becoming closer in pursuing the sustainability that, since decades, all the global plans are heading to. We can define the study of these themes as relatively young; it follows, in various areas, the historical and economic situations of the world, particularly the financial transitions that, up to a few decades ago, saw the world divided in north and south, distinguishing between Developed and Developing Countries, arriving to the "Fourth World" definition due to the globalization, where to the new developing countries have the highest levels of polluting emission towards the environmental matrices. The UN, since its birth in 1945, emphasised the peace keeping, human rights and the fair social-economic development (as being the necessities of that time), yet no mention of was made about the environment. At the end of the sixties the importance and gravity of the environmental issues have been detected and, in some cases, turned out to be irreversible. This in the moment where the relation between economy and environment was born, and for the first time with a negative connotation.

The UN Conference for the Human Environment held in Stockholm in 1972 was the first organized by the UN on environmental themes, and officially inaugurated the global interest on the so called "Environmental matters". To this will follow more frequent actions, at all levels but, with regard to

*Corresponding author: Brunella Brundu Department of Economics and Business (DiSEA) University of Sassari, Italy the issues generated in the climate areas (climate change); the formalization of joint actions at a global level took place during the UN Conference on Environment and Development UNCED in Rio de Janeiro in 1992, from where sprung the United Nations Convention on Climate Change UNFCCC, who's target is to stabilize the concentration of greenhouse gases in the atmosphere. This target becomes binding in the Kyoto Protocol adopted in 1997, in which there is the commitment of the developed countries to reduce, for the period 2008-2012, the total amount of emissions of $5 \%$ compared to the 1990 level. The protocol, signed by more than 180 countries and entered into force in 2005 , foresaw the ratification of 55 countries producing the $55 \%$ of the polluting emissions, whilst offering the possibility not to take any binding measure to the developing countries. The concern over climate change brought to more accurate studies about global warming, the WMO, World Meteorological Organization and the United Nation Program for the Environment (UNEP) will form in 1988 the Intergovernmental Panel on Climate Change - IPCC, whose reports provide evaluations and updates on the world situation.

The attention for the climate changes is increasingly pressing, since 1995 the Conference of Parts (COP) in the UNFCCC is held annually in various cities around the world. The last one was held in Marrakech, Morocco, in 2016. During these sessions actions, strategies and new deals are established. The one held in Paris (COP21) in 2015 has a particular importance, where the agreement signed by 195 countries on the world climate has a universal character, defining a global action plan that is legally binding. At the Paris conference all 
the single countries presented climate national action plans, and the European Union by 2030 to reduce at least by $40 \%$ its greenhouse emissions compared to 1990 levels. One key element is the mitigation, that is emission reduction to limit the increase to $1.5^{\circ}$.

The European Environmental Community Policy was born in 1973 with the adoption, by the Council of Ministers, of the first Environmental Action Program (PAA). The Treaties of Rome, establisher for the European Community in '57, didn't provide any rule for environmental care, but one fundamental path toward that direction is the "Single European Act (AUE), signed in February 1986 and ratified in 1987, which modified and completed the Treaties of Rome, expanding the power of the Community in different sectors and perfecting the decision-making procedures." (http://www.rgs.mef.gov.it). Among the novelties introduced, some political areas including the environment, are formally incorporated. In 1992 the government of the 12 countries constituting the European Community signed the Maastricht Treaty, where the environmental themes are strengthened and the following four objectives were set: safeguard, care and improving of the quality of the environment, human health protection, controlled use of the natural resources; international promotion for measures aimed to sort problems at a regional and world level. In the Art. $130 \mathrm{R}$, par. 2, it is established that the principle in which "the needs linked to the environment safeguard have to be inserted in the definition and actuation of the other common politics" (Segre, Dansero, 1996, Pag. 12), affirming the concepts of sustainable development and integration. With the Amsterdam Treaty of 1997 this principle will become one of the main targets of the European Union. The subsequent action programs for the environment see a Europe equipped with instruments suitable for prevention and precaution and formulates the basic principles to implement them, but is the Fifth Environmental Action Program (for a sustainable and durable development) formulated for the period 1992-2000, that marks a significant phase of the evolution in the environmental policies. This, according to the agreements of the Rio de Janeiro Conference, acts towards the environmental sustainability transforming the development model of the community policy through the use of legal, economic and financial tools in order to modify the bad behaviour against the environment. Thanks to multilateral (UNEP, OECD, European Council) or bilateral agreements, the community aims to the cooperation between countries against environmental issues, like the reduction of the ozone layer, the loss of biodiversity, deforestation, and finally the climate change issue have been placed in a prominent position. Climate change represent, in facts, a global issue that can be sorted only through joint actions at an international level (http://www.interreg-enplan.org/). In the VI Action Program for Evironment $(2001-2010)$ this issue is recognized as the main challenge for the next 10 years, and the target is to reduce the greenhouse gases at a level that will not affect the planet climate.

In march 2000 the European Commission issued the European Program for Climate Change (ECCP) whose purpose is the reduction of the greenhouse gases, the main actors in the increase of the world temperature. The strategy used have been defined ad "doubletrack" as being based on the Green Book that expect an exchange of the emission rights between the EU countries, and is addressed to the energy field and to the big industrial plants, while the second step includes measures finalized to the lowering of emission levels coming from specified sources. (http://europa.eu).

Finally, the 7th Environmental Action Program (Fine Living within our planet borders) (2013-2020) identifies three priority areas: protecting nature and enhancing ecological resilience, promoting low-carbon growth with efficient use of resources, and the reduction of threats to the health and to the well-being of citizens linked to pollution, chemicals and effects of climate change.

These steps are divided in nine priority objectives that address the problem in a holistic way; the sixth in particular, calls for investment to support climate and environmental policies, and to consider the environmental externalities. To this end the PAA proposes to allocate at least $20 \%$ of the $2014-2020$ EU budget to climate change mitigation and adaptation (http://ec.europa.eu/). The Program derives from the Europe 2020 Strategy, which was launched in 2010 to counter the economic crisis, and aims to direct the European Union's economy over the next decade. A strategy for smart, sustainable and inclusive growth, that's the title of the document, includes among the five goals of achieving the "20-20-20" target, by 2020, in climate and energy: reducing gas emissions by $20 \%$ compared to $1990 ; 20 \%$ of the energy needs from renewable sources; $20 \%$ increase in energy efficiency. This brief excursus demonstrates that the European Union, in line with global trends, pursues and has high quality standards developed over the decades. It is highlighted how policies and strategies are implemented in the environmental and more climatic environment, promoting low carbon technologies and adaptation measures.

"The EU's Environmental Policy is based on Articles 11 and 191-193 of the Treaty on the function of the European Union. Under Article 191, fighting climate change is an explicit objective of EU environmental policy". The general objective is therefore sustainable development for the European Union, which is committed to "ensuring a high level of environmental protection and improving its quality" (Article 3 of the Treaty on European Union) (http: // eur lex.europa.eu/).

\section{Climate change and its effects}

Climate change can be evaluated though the variations in the average and/or through the variability of several indicators that persist for an extended period of time. It can be due to natural processes and changes in the composition of the atmosphere or even sought after through land use (WGII AR5). The climate changing produces some important phenomena, with the most relevant schematized below, with the use of the Climate-ADAPT statistics.

Over the last 90 years, the snow layer in the northern hemisphere has dropped significantly, recording an average reduction of $7 \%$ in March and April and by $47 \%$ in June, 1967-2015. This change affects the reflectivity of the Earth's surface, water resources, flora and fauna and their ecology, agriculture, forestry, tourism and in particular snow sports, transport and energy production. Since one third of the surface of the emerged lands is covered by snow for a certain period of the year, part of the solar energy is reflected and therefore not absorbed. Therefore, the decrease in its coverage increases the amount of sunlight absorbed by Earth, 
producing an increase in temperature (Dahlman, 2016). Satellite measurements also show a rise in the average global sea level due to climate change, the root causes of which is in the melting glaciers and changes in the water cycle. The rise, albeit lower than that recorded in the normal sea level fluctuations caused by tides, produces storm waves that are capable of causing significant damage to coastal areas (Vitousek et al., 2017). Rain has also changed, increasing or decreasing in various countries, changing their distribution. In the twentieth century rainfall increased in northern Europe by $10-40 \%$, while in Italy it decreased by $5 \%$ in the north and by $15 \%$ in the south (Dore, 2005). Another phenomenon, as mentioned above, is the global warming: in Europe the average temperature for the decade 2004-2013 was $1.3^{\circ}$ higher compared to pre-industrial times, and according to Clime ADAPT is expected an increase of about $2.4^{\circ}$ and beyond. Since 1880 the average duration of summer heat waves in western Europe has doubled and the frequency of hot days almost tripled. In the new millennium have been recorded an increase of deaths and morbidities in Europe, caused by the alternation of hot and cold waves in Europe, thus decreasing overall well-being. Climate events may have devastating effects on humans such as widespread disasters, hunger and diseases caused by drought and flooding, especially in the poorest countries. According to the World Health Organization (2003), the statistical distribution of extreme events will increase as temperatures rise even if not linearly.

Finally, the Alpine glaciers have lost about two-thirds of their volume since 1850 , with an acceleration since 1980, and showing an inexorable loss trend.

\section{Social economics impacts derived from climate change}

Climate change will have impacts of economic and environmental relevance, which will produce indirect impacts on any human activity with different intensity in different places (Bigano, 2013).

The estimation of the impacts of climate change can also be achieved by considering the social aspects, droughts and floods, for example, have caused and cause large displacements of populations; already in 2009 the International Organization for Migration (IOM), provided that 25 million to 1 billion people could migrate from their home country due to climate change over the next 40 years.

The decrease in the effectiveness of poverty and foodshortages reduction programmes in the world, and the negative impacts on development actions in those economic sectors that are more easily affected by climatic conditions, in particular in agricolture, are particulartly noteworthy. This phenomenon is amplified by non-climatic factors such as consumption and, therefore, exhaustion of natural resources determined by anthropogenic environmental and demographic pressure (Karfakis et al., 2011). The report on "The Climate Change, Impact and Vulnerability in Europe 2016" of the European Environment Agency (EEA), the IPCC reports and various other publications provide a review of the main economic impacts of climate change.

Among the factors that will affect the current socio-economic system, as mentioned above, the main one is the rise of the seas due to glacial melting. Europe's coastal areas rich in inhabited areas, economic activities and natural ecosystems with high biodiversity values will be forced to engage adaptation policies such as dam construction, coastal repopulation, coastal ecosystem rehabilitation, targeted territorial planning associated with integrated coastal zone management, and will need to further enrich their instruments by developing maps of hazard and flood risk. Coastal flooding that has hit millions of people in Europe since 2000 has compromised human health in various forms, in addition to the more drastic form of drowning, causing heart attacks, injuries, infections, exposure to chemical hazards and consequences for mental health. Disruption of services, including health services, shortages of drinking water, sanitation and transport, are non-secondary factors affecting the economy of the territories concerned (EEA, 2017).

In 1998-2002 Europe "suffered about 100 floods that caused 700 victims, the transfer of about half a million people and at least 25 billion euros of economic losses for the insured damages." These floods involving an area of about one million square kilometers affected about $1.5 \%$ of the European population (EEA, 2005, p. 2; Carraro et al., 2007). The energy sector is also an example of the economic sector that is particularly vulnerable to climate change, production and consumption are assessed on the basis of temperature and extreme phenomena. The overall effect on energy demand will depend on the trends of meteorological parameters at local and seasonal levels (Gaudioso D., 2012).

The processes induced by climate change are therefore factors of impact on the socio-economic component and determine the risks, listable in dangers, vulnerabilities and exposures, with socio-economic component influencing the anthropogenic component of climate change. The same socioeconomic processes carried out along specific paths through adaptation and mitigation actions and environmental policies that consider governance models can affect the risk. A uniform and homogeneous system of environmental governance is essential to ensure proper management of the global ecosystem, a system suitable to coordinate environmental protection measures that still sometimes appear fragmented, preventing balanced management of available resources and leading overlaps in international action on matter (Lenzerini, 2008).

\section{Conclusions. Territorial governance, a useful tool}

The management of climate change adaptation and mitigation processes is very complex and therefore requires a multilevel governance approach for a more effective local public policies and development strategies. "It is about creating a system through which the responsibility for defining the policies for adaptation and implementation is distributed between different levels of government and institutions, with different modes and tasks in relation to the administrative actions of programming, control, evaluation and management in play. In this sense, Public Administrations are called to define appropriate ways for implementing climate change actions " (Pernice et al., 2017).

The resulting scenario from the analysis of climate change show unequivocally that the territory over time will, in some cases, significantly change, deeming necessary timely choices from government agencies. For these reasons, it is important to find solutions through effective policies geared to ensure adequate responses to change both by mitigation and adaptation measures. The need to integrate climatic data with 
those that are environmentally friendly and socially owned by the land arises from the need to develop appropriate development policies to suit the changing scenarios and appropriate governance tools.

Climatic variables, factors affecting economic and environmental variables, and associated indicators, are very complex and, in order to generate comprehensive responses that support decisions, they need adequate IT systems. It is therefore necessary to create an articulated system that acquires historical data series, continuous monitoring based on effective indicators, elaborates possible scenarios by integrating the results into a GIS-based system that puts the decision maker in the best conditions to make choices (Brundu, Manca, 2016).

The system to be used to assist the territorial governance for climate change must provide, for the creation of a database that collects informations strictly based on climate, ecological, environmental and socio-economic indicators and has the ability to store them in a standardized way. The system, having to deal geographically or geographically referred to survey territories, requires the use of a GIS software for the creation of a Geographic Information System connected to the database.

The system, as well as allowing to display data within the spatial scope of the study, has the ability to perform sophisticated analysis through spatial queries and provides useful answers to the governance of the territory. The same system, through an intelligent model (built on the basis of a Bayesian network), is able to identify the appropriate correlations between them, based on historical re-constructed sets of different indicators, and to predict through a probabilistic model the risks for the territory arising from climate change. This capability allows the system to find an important use in defining territorial policies to mitigate or adapt the planning choices in the climate change in progress.

\section{Bibliography}

Anthoff D., Nicholls R.J., Tol R.S.J., "The economic impact of substantial sea-level rise", Mitig Adapt Strateg Glob Change, 2010, pp. 321-335.

Bigano A., "Un forte impatto sul turismo, come può rispondere 1'Italia?", Ecoscienza, n. 5, 2013, pp. 66-68.

Capecchi G., Parisi N., Santini A., "L'Organizzazione delle Nazioni Unite", Liuc Papers, n. 2, Serie Impresa e Istituzioni, 18, 2002, pp. 1-44.

Brundu B., Manca I., La geo-governance: tecnologie smart per la sostenibilità, XX Conferenza Nazionale ASITA, 8-10 novembre 2016, Cagliari, 2016, pp. 103-110.

Carraro C., Crimi J., Sgobbi A., La valutazione economica degli impatti dei cambiamenti climatici in Italia e delle relative misure di adattamento, APAT - CMCC, 2007.

Commissione delle comunità europee, L'ambiente in Europa: quali direzioni per il futuro?

http://www.interreg-enplan.org/

Commissione delle comunità europee, Ambiente 2010: il nostro futuro, la nostra scelta - Sesto programma di azione per l'ambiente http://www.isprambiente.gov.it/ files/agenda21/2001-sesto-piano-azione-ambientale.pdf

Commissione europea, VII Programma d'azione ambientale. Vivere bene entro i limiti del nostro pianeta http://ec.europa.eu/environment/pubs/pdf/factsheets/7e ap/it.pdf

Convenzione quadro delle Nazioni Unite sui cambiamenti climatici

https://www.admin.ch/opc/it/classifiedcompilation/19920113/201310030000/0.814.01.pdf

Dahlman L.A., Climate Change: Spring Snow Cover, 2016

https://www.climate.gov/news-features/understandingclimate/climate-change-spring-snow-cover

Dore M.H.I., "Climate change and changes in global precipitation patterns: What do we know?", Environment International, n. 31, 2005, pp. 1167-1181.

EEA Briefing, Cambiamento climatico ed alluvioni in Europa, 2005.

EUR-Lex, Ambiente e cambiamenti climatici http:// eurlex. europa.eu/summary/chapter/environment.html?locale $=\mathrm{i}$ t\&root_default=SUM_1_CODED\%3D20

European Environment A-impacts and vulnerability in Europe 2016. An indicator-based report, n. 1, 2017.

European Commission, Cambiamento climatico: la Commissione vara il Programma europeo per il cambiamento climatico e definisce una strategia a doppio binario per la riduzione delle emissioni, 8 marzo $2000 \mathrm{http}: / /$ europa.eu/rapid/press-release_IP-00232_it.htm?locale=en

European Commission, Azione per il clima. Accordo di Parigi

https://ec.europa.eu/clima/policies/international/negotiation $\mathrm{s} /$ paris_it

Gaudioso D., "L'impatto dei cambiamenti climatici sul sistema energetico italiano: verso una strategia nazionale di adattamento", Energia, Ambiente $e$ Innovazione, ENEA, 6 2012, pp. 46-49.

International Organization for Migration (IOM), Migration, Environment and Climate Change: Assessing the evidence, 2009.

Karfakis P., Knowles M., Smulders M., Capaldo J., Effects of global warming on vulnerability to food insecurity in rural Nicaragua, ESA Working Paper, n. 11-18, 2011.

Lenzerini F., "La governance ambientale nel diritto internazionale", in M. Montini e M. Alberton (a cura di), La governance ambientale europea in transizione, Giuffrè, Milano, 2008, pp. 1-28.

Segre A., Dansero E., Politiche per l'ambiente, UTET, Torino, 1996.

Padovani L. M., Carrabba P., Di Giovanni B., "Da Rio a Johannesburg: verso lo sviluppo sostenibile", Energia, Ambiente e Innovazione, ENEA, 2, 2003.

Pernice M., Balestrieri M., Pusceddu C., - Ministero dell'Ambiente e della Tutela del Territorio e del Mare, Direzione Generale per il Clima e l'Energia, Il ruolo della pubblica amministrazione nell'adattamento ai cambiamenti climatici. Un approfondimento a FORUM PA 2017 http://forumpa2017.eventifpa.it/

Vitousek S., Patrick L., Barnard P.L., Charles H., Fletcher C.H., Frazer N., Erikson L., Storlazzi C.D., "Doubling of coastal flooding frequency within decades due to sea-level rise", Scientific Reports, n. 1399, 2017.

World Health Organization, Climate change and human health. Risks and Responses, Geneva, 2003. 